spiratory valve, and capable, by yielding edges, of fitting the face closely.

At present, the expense is a serious drawback, and the smell is generally considered to be highly objectionable; but neither of these should prevent it from obtaining from the profession a fair and candid trial.

I think it very probable that we shall be placed in the same position with regard to anæsthetics as to many other medicines. We shall have, most probably, hereafter, to select the most appropriate in each particular case. Thus, as in prescribing mercury, we select the form best adapted to the case before us, so in the production of anæsthesia, it will be our wisdom to select the anæsthetic which will best suit the requirements of the case before us. Where the operation only involves the skin, we shall do well to employ Dr. Arnott's method, which is most assuredly deserving of more consideration, and of more extended use, than it has hitherto met with. When, on the other hand, the operation is more severe, and likely to be longer continued, we may choose amylene: and we shall be the more led to do this, if from any reason we suppose that our patient will not bear well the use of chloroform. Bu when we want to produce the most thorough unconsciousness, when we require to keep up the condition for a long time, and especially when, from any circumstance of the operation, we cannot apply the inhaler with sufficient assiduity for maintaining the effect of amylene, then we shall, I believe, still have recourse to chloroform, which, although it appears to be the most dangerous of the anæsthetics at present in use, yet has the great advantage of being by far the most effective.

\section{CASE DEMONSTRATIVE OF THE POWER OF BELLADONNA IN ARRESTING THE SECRETION OF MILK.}

By JoHn Burrows, Esq., Liverpool.

Havina had a large midwifery practice. I have witnessed much suffering and annoyance from inflammation and suppuration of the mammæ, which arose in many instances from a copious secretion of milk, that distended the breasts, pressed upon the nerves, and increased the action of the circulatory apparatus, and thus produced inflammation, with some of its painful and debilitating consequences. In numerous cases, I am persuaded, these painful effects would have been prevented if $I$ had known of a remedy which would either have suspended the maternal function, or entirely arrested it. Such a remedy, I believe, we have in belladonna. The following case confirms this view of its therapeutic power.

Case. Mrs. R., aged 26 years, commenced the woaning of her second child on March 10th, 1857. On March 11th, I saw her. She complained of great pain of the left breast, which was inflamed, much distended, and very hard. She directed my attention particularly to a wide, callous, and painful prominence, that resembled a thick convex belt, which stretched from the mamma to the clavicle. I prescribed the diluted extract of belladonna, and directed it to be applied as in the former case. I saw her again on the following day. She said her breast continued disterided and painful. I then had a momentary doubt of the efficacy of my remedy. No sooner had the thought crossed my mind than she said, "I washed off your salve, and put on sticking plaster, at the recommendation of a female friend of considerable experience." I spoke to her of the impropriety of calling in a medical man, if she would not follow his advice. She felt the remark, and replied, "I will take off the plaster, and apply your preparation." I urged her to do so without delay. Having lost some valuable time, I deomed it necessary to combine with the application of the extract the administration of the purgative mixture, with the wine of colchicum. Had there been no delay, I intended to test the antilactific power of the remedy alone, without the combined influence of any other. Time having been lost, I was afraid of trusting to it, lest suppuration should ensue.

On March 13th, I visited her. She met me with a smile, and exclaimed, "My breast is better; the pain is gone, and the fulness reduced." She continued the application till the following morning, when the breast was cool, pale, and flaccid, and the elevated hardened integument, that stretched from the breast to the clavicle, diminished in size, softer to the touch, and free from pain. The secretion of milk is arrested, there being no spontaneous dribbling from the nipple; nor can any milk be squeezed out of the breast.

\section{Cltimital âdecture}

EMPLOYMENT OF THE OPHTHALMOSCOPE IN THE INVESTIGATION OF DEEP-SEATED DISEASES OF THE EYE.

By Hox mes Cооте, Esq., F.R.C.S., Assistant-Surgeon to St. Bartholomew's Hospital; late Surgeon to the British Hospital at Renkioi, Dardanelles.

The difficulties so often experienced by the surgeon in determining the exact seat or nature of the different diseases affecting the structures of the eye posterior to the iris, render any discovery acceptable by which diagnosis may be facilitated; and hence the ophthalmoscope, which illuminates the interior of the globe and brings before the observer morbid changes in the choroid coat, or in the retina, heretofore unknown, is attracting at the present moment particular attention.

The merit of invention of this instrument, accorded by the French to a Greek physician, named Anagnostakis, and claimed by the Germans as their own, is in truth due to an Englishman, Mr. William Cumming, formerly house-surgeon to the London Hospital, who wrote in the twenty-ninth volume of the Transactions of the Royal Medical and Chirurgical Society, a paper, the object of which was to shew that the healthy human ere is equally or nearly equally luminous as the eye of the cat, d.ig, etc., when observed under favourahle circumstances; and t'at the abnormal appearance or want of luminosity may be a!plied to the detection of changes in the retina and the posterior part of the eye.

The circumstances necessary for seeing the luminosity may be arranged as follows.

1. That the eye must be at some distance from the source of light-the distance being greater in proportion to the intensity.

2. That the rays of light diffused around the patient (and sometimes around the eye itself) should be excluded.

3. That the observer should occupy a position as near as possible to the direct line between the source of light and the eye examined.

Mr. Cumming supports his statements by the narration of several cases of amaurosis, which he witnessed at the Royal Ophthalmic Hospital, Moorfields. Had it been this gentleman's good fortune to have called German his mother-tongue, with what enthusiasm would this discovery have been welcomed in England! As it was, the paper was read, published, and forgotten, until lately, about ten years after it was written, when the impress of value to the observations has been accorded by the foreign schools.

In 1847, Mr. Cumming's experiments were repeated by Brücke at Vienna. The former threw light upon the face of a person ten to twelve feet from the candle, intercepting the side rays, and endeavouring to bring his own eye as near to the flame as possible. The latter also used a candle, but held between it and his face, as high as the summit of the flame, a screen, over which he looked into the illuminated organ.

In 1854, two other Englishmen were engaged in this subject, namely, Mr. Wharton Jones and Mr. Babbage. Indeed, the latter had constructed an instrument, consisting of a bit of plane glass mirror, with the silvering scraped off at two or three spots in the middle, fixed within a tube at such an angle that the rays of light falling on it through un opening in the side of the tube were reflected into the eye to be observed, and tc which one end of the tube was directed.

It is unnecessary to repeat how Helmholz, E. Jäger, Coccius, Ruete, Graefe, and Anagnostakis, with others, have worked with laudable perseverance, until the instrument now in use has been constructed. It carries out very well the principles laid down by Mr. Cumming, and needs only a little practice to become manageable in the hands of any one.

Before proceeding to describe some of the cases in which important information is gained by the use of the ophthalmoscope, I may remark that the usual depreciatory cry of obstructive mediocrity has been already raised against this as against every other novel instrument, either in medicine or surgery. We are told that the employment of the light injures the eve ; that it shews nothing; that what it does shew, cannot be rectified. I have often remarked to you that a precisely similar cry was uttered of the stethoscope, the early general employment of which is quite within my professional recollections. The same enlightened remarks will be made on the next discovery of a 
similar class, but experience proves that they do not affect the ultimate success of that which is true.

I apprehend that one great advantage likely to result from a more accurate knowledge of the pathology of the deep-seated affections of the eye, will be to connect ophthalmic surgery more closely with general medicine; to render it less a speciality; and to establish far more scientific and well-grounded principles of constitutional treatment. Already have the consequences of scrofula, gout, rheumatism, syphilis, Bright's disease of the kidney, on the sight, been recognised; but we want the first step in the further inquiry-namely, the nature of the morbid changes in the affected organ.

Syphilitic iritis is a disease which is generally very easily controlled by proper treatment; namely, the abstraction of blood and the administration of mercury. Occasionally, though rarely, patients do not bear blood-letting. In other cases, mercury is inadmissible from the beginning; or, at some later period, when other medicines have to be substituted. But at the same time, let it be remembered, that iritis may run its course without treatment, and leave the patient very useful vision.

A case which, after the subsidence of the active disease, leaves the patient with vision impaired for a month or six weeks, but slowly progressing to complete recovery, affords useful matter for ophthalmoscopical investigation.

A young man was under my care in St. Bartholomew's Hospital, suffering from acute syphilitic iritis, in the month of September 1856, having neglected himself for a fortnight previously. His disease yielded to the usual treatment, but left him with a mist before his sight, which was unfit for any occupation requiring minuteness. I examined this patient with the ophthalmoscope early in January 1857, with the expectation of finding traces of inflammatory deposit in the choroid membrane. In this, however, I failed; but behind and to the side of the crystalline lens, and in the vitreous humour, there were opaque membraniform deposits, which prevented the ready transmission of light. Experience had taught me that ultimately the eyes would recover themselves; and I ex. pressed myself to the effect in confident terms to the patient. He presented himself at the hospital on March 12th, when his vision was as perfect as ever. The morbid deposits had disappeared.

Dr. Heymann, of Dresden, remarks, that in iritis two forms of morbid deposit are noticed. 1. A sparing exudation from the iris, but with turbidity of the aqueous humour. 2. Frequently recurring hypopion. In the first form, the opacities in the vitreous humour were fine, filamentous, or membranous, and depended upon inflammation of the ciliary bodies, and perhaps of the anterior part of the choroid. In the second, it was seen that the vitreous humour was turbid, the choroid coat redder than usual, and studded with yellow inflammatory deposits. The veins of the retina were very dark and dilated. In this form of disease, the vitreous humour may be occupied by a network of lymph.

The influence of Bright's disease, or granular degeneration of the kidney upon the organs of vision, is becoming daily subject of greater interest. The drawing which $I$ here present was taken from an amaurotic patient of intemperate habits. The papilla of the optic nerve is swollen; the branches of the central vessels of the retina are less visible than natural; there are small and distinct deposits of lymph about the choroid membrane. Of the history and progress of this case, $I$ unfortunately know nothing.

Landouzy is said to have first published an account of the connexion between Bright's disease and amaurosis. But Blodig found only three cases in illustration of this combination during the five years he studied in the ophthalmic clinic of Vienna.

At Dresden, Dr. Heymann found in an eye of a patient so diseased: 1. All the transparent structures normal; 2. The choroid of its usual vascularity; but the papilla of the optic nerve was twice its normal size.

In a second case, the vitreous humour was found to be turbid.

In a fatal case, the following post mortem appearances were observed. Upon division of the globe, the vitreous humour did not flow out, but clung to the anterior and the posterior sections. The anterior part of the choroid shewed deficiency of pigment in the choroid, corresponding to external blue discoloration during life. In the posterior segment, the macula lutea was abnormally marked. About one or two lines from the entrance of the optic nerve, which was natural, there was a ring of yellowish white deposits, about twenty in number. By the aid of a magnifying glass, other and smaller spots were seen in the neighbourhood. The microscope showed that these spots were instances of granular fatty degeneration of the retina, which separated more easily than natural from the choroid.

Seventeen years ago, long before the microscope was in general use or the ophthalmoscope invented, the following case came before my notice.

Thomas P., aged 22, a printer and compositor, a man of in temperate habits, was admitted into St. Bartholomew's Hos pital, under Mr. Lawrence, with amaurosis, considerably advanced in both eyes. The sight had been gradually failing for the last four months, but without heat about the temples or pain in the head. There had been no dark spots or muscæ volitantes. The pupils moved sluggishly upon exposure to light, which however caused no pain.

Feb. 23rd, 1840. Five grains of blue pill were ordered to be taken thrice a day. He was cupped from the neck to ten ounces.

Feb. 24th. He stated to-day that he had of late suffered much pain from swelling of the legs, which he attributed to his constant habit of standing. He was suffering from bronchitis of both lungs.

March 1st. He died of the disease of the chest.

Examination of the Eyes after Death. The external appearance of the organs was natural. The optic nerve was unaltered in appearance, perhaps flatter than usual; the transparent structures were healthy, but near to the optic papilla in both eyes there was an extravasation of blood in the retina visible to the unassisted eye.

The bronchi were full of secretion; the lower part of the lungs was consolidated.

The abdominal viscera were not minutely examined.

I believe that this was a case of Bright's disease, and that in consequence, those granular changes occurred in the arteries of the retina, which Virchow has described as common under such circumstances in the capillaries of the brain.

Sufficient has here been said to show the importance of further investigations upon the subject.

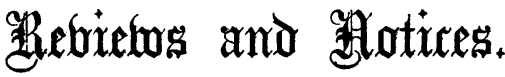

On Rheumatism, Rheumatic Gout, and Sctatica; their Symptoms, Pathology, and Treatment. By Henra W. Futuer, M.D.Cantab., Assistant-Physician to St. George's Hospital, etc. pp. 464. London: Churchill. 1856.

The first edition of Dr. Funder's excellent work on Rheumatism was carefully reviewed in the Association Medical JourNaL for February 25, 1853 ; it will not be necessary, therefore, to do more now than to point out briefly the additions which have been made in the second edition.

The work has been enlarged by about sixty pages; and the additions chiefly consist in remarks on various remedial measures to be used in rheumatic gout, in chronic rheumatism, and sciatica and other forms of neuralgic rheumatism. In the chapter on chronic rheumatism, Dr. Fuller thus brings under notice the merits of sassafras, diluents, sulphur, mezereon, arsenic, various sedatives, aconite, the hot iron, the frigorific mixture of Dr. J. Arnott, and oil of turpentine. Subjoined is a brief abstract of the remarks made on some of these remedies.

Sulphur, in doses of half-a-drachm, three or four times in the day, and aided by the sulphur vapour-bath, is regarded by the author as one of the most reliable remedies for the removal of chronic muscular pains. Its use, however, should be restricted to muscular and neuralgic rheumatism. This drug, Dr. Fuller observes, has doubtless contributed not a little to the reputation of the powder termed the "Chelsea Pensioner".

In his chapter on Sciatica, Dr. Fuller has some noteworthy remarks on the effects of sulphur applied externally.

"Nothing proves more generally efficacious than sulphur applied externally. Whatever its mode of operation, the fact remains that, employed in this manner, it often subdues pain which has persisted in spite of all other remedies. In many parts of England, the sulphur ointment of the Pharmacopeia is a favourite remedy amongst the poor for the cure of rheu- 